\title{
AN EVALUATION OF THE STABILITY OF MOULD FLUX PROPERTIES IN THE PROCESS OF CONTINUOUS STEEL CASTING
}

\begin{abstract}
This paper presents research on the mould slag formed on the basis of two mould fluxes. In the conducted industrial experiments, slag was sampled in equal time intervals between adding subsequent portions of mould flux. The research focused on the an evaluation of the stability of slag parameters by assessing the change in its liquidus temperature. It was shown that a mould flux needs to be assessed individually taking into account the casting process parameters and the steel cast grade.

Keywords: mould flux, alumina inclusions, liquidus temperature, flux consumption
\end{abstract}

\section{Introduction}

The improvement of the mould flux constitution is a process, which has already been in progress for over 50 years. At the beginning, fly ashes mixed with fluxes of $\mathrm{Na}_{2} \mathrm{O}$ and $\mathrm{CaF}_{2}$ type were applied. The first trials in the continuous casting process were conducted in the early $60 \mathrm{~s}$. It was found then that the application of mould fluxes, contrary to oil, allows the correct value of heat transfer coefficient to be obtained, and consequently the surface quality of the strand to be improved. In the research on mould fluxes, this is key to understanding how they act and how various factors influence their correct performance. Very soon, it was found that the stability of mould flux performance parameters is vital for the continuous steel casting process, and therefore measures to implement the top technological standards to mould flux production were adopted very early.

The basic components of mould fluxes can be broken down into the following groups [1]:

- Network formers $\mathrm{SiO}_{2}, \mathrm{Al}_{2} \mathrm{O}_{3}$,

- Network breakers $\mathrm{CaO}, \mathrm{MgO}$,

- Fluxes $\mathrm{Na}_{2} \mathrm{O}, \mathrm{K}_{2} \mathrm{O}, \mathrm{Li}_{2} \mathrm{O}, \mathrm{CaF}_{2}, \mathrm{FeO}, \mathrm{MnO}, \mathrm{B}_{2} \mathrm{O}_{3}$,

- Others $\mathrm{TiO}_{2}, \mathrm{ZrO}_{2}$,

- Carbon.

In most cases a mould flux is comprised of calcium aluminosilicates with the addition of fluxes [2,3]. The mould flux basicity measured as a ratio of $\mathrm{CaO} / \mathrm{SiO}_{2}$ ranges from 0.7 to 1.4 . The selection of mould flux basicity is influenced primarily by the grade of the steel cast and the casting speed. Viscosity is an important parameter characterising a mould flux. In the casting process, a change in the mould flux viscosity is usually caused by a change in the $\mathrm{Al}_{2} \mathrm{O}_{3}$ content. Changes in the $\mathrm{Al}_{2} \mathrm{O}_{3}$ content are caused by various effects, but the most important are oxygen inclusions floating to the slag from the steel $[4,5]$ and the reaction of $\mathrm{Al}$ dissolved in the steel with $\mathrm{SiO}_{2}$, as follows:

$$
3\left(\mathrm{SiO}_{2}\right)+4[\mathrm{Al}]=2\left(\mathrm{Al}_{2} \mathrm{O}_{3}\right)+3[\mathrm{Si}]
$$

Fluxes are added to the mould flux in order to reduce its liquidus temperature and viscosity. The presence of $\mathrm{FeO}$ and $\mathrm{MnO}$ in the mould flux should be restricted because the oxygen potential in the slag increases when the content of these oxides increases. However, a positive impact of both mentioned components should be noted as they reduce the transfer of heat by radiation. The $\mathrm{FeO}$ pickup is usually $1 \%$, and the $\mathrm{MnO}$ pickup depends on the Mn content in the steel. Other mould flux components, such as $\mathrm{TiO}_{2}$ often occur as mineral contaminants, although they also happen to be added intentionally. Titanium has a tendency to form $\mathrm{Ti}(\mathrm{CN})$, leading to an increase in viscosity and a deterioration of the mould flux lubricating properties.

Carbon as a component of the mould flux controls its melting rate. It is important to correctly understand the mechanism of this effect, where the fact that slag does not wet carbon is key. The droplets of liquid slag cannot agglomerate until carbon particles get oxidised. Therefore, the more carbon in the mould flux, the slower its melting rate. The effect of the reduction of the grain size of the carbonising material in the mould flux is similar. Other factors having a positive impact on the process concerned are the heat transfer coefficient growing perpendicularly to the steel meniscus and the declining mould flux density.

Note that the mould flux melting rate is closely related to its consumption rate in the casting process. Hence, all factors influencing the mould flux melting rate need to be known.

\footnotetext{
AGH UNIVERSITY OF SCIENCE AND TECHNOLOGY IN KRAKOW, FACULTY OF METAL ENGINEERING AND INDUSTRIAL COMPUTER SCIENCE, AL. MICKIEWICZA 30, 30-059 KRAKOW, POLSKA

\# Corresponding author: jfalkus@agh.edu.pl
} 
Basic functions of the mould flux can be characterised as follows:

- To prevent solidification of the steel meniscus by reducing heat loss in a vertical direction,

- To prevent oxidation of the melt,

- To lubricate the forming shell,

- To stabilise the flux of heat extracted horizontally,

- To absorb non-metallic inclusions floating out.

\section{Mould flux properties}

Due to the complex mould flux impact, the parameters characterising its properties must be controlled and adjusted to the expected casting conditions. Certainly, viscosity is one of the most important mould flux parameters, as it is decisive to:

- The consumption of mould flux and consequently the quality of shell lubrication,

- $\quad$ Slag entrapment,

- SEN erosion [4].

The measurement of mould flux viscosity is usually conducted for an average temperature of $1300^{\circ} \mathrm{C}$. However, many authors have indicated experimental difficulties, which significantly affect the measurement accuracy. Models allowing viscosity to be estimated on the basis of the mould flux chemical constitution are also present in the literature.

Measurements of characteristic temperatures determined for mould fluxes are relatively more simple. Typically, they constitute a set of two temperatures: the liquidus temperature and the temperature at which a rapid change in the mould flux viscosity occurs, the so-called break temperature. Appropriate measurements are always required to determine these temperatures accurately. Otherwise, the liquidus temperature $T_{\text {liq }}\left({ }^{\circ} \mathrm{C}\right)$ value can be estimated according to the equation:

$$
\begin{aligned}
T_{\text {liq }}= & 1191+11.4\left(\% \mathrm{SiO}_{2}\right)-11(\% \mathrm{CaO})+ \\
& +4.2\left(\% \mathrm{Al}_{2} \mathrm{O}_{3}\right)+5.7(\% \mathrm{MgO})+ \\
& -10.1\left(\% \mathrm{Na}_{2} \mathrm{O}\right)-15.8\left(\% \mathrm{~K}_{2} \mathrm{O}\right)+1.9(\% \mathrm{~F})+ \\
& +8.3\left(\% \mathrm{Fe}_{2} \mathrm{O}_{3}\right)+11.6(\% \mathrm{MnO})
\end{aligned}
$$

It is assumed that the estimation accuracy is $\pm 30 \mathrm{~K}$

It is much more complex to determine the break temperature. The value of this temperature determines the thickness of the solid and liquid slag layer between the strand and the mould. An increase in $T_{b r}$ causes an increase in solid layer thickness. It should be emphasised that in practice the value of $T_{b r}$ does not depend on the mould flux only, it depends also on the casting parameters. The mathematical estimation of the break temperature is possible on the basis of the equation:

$$
\begin{aligned}
T_{b r}= & 1120-3.3\left(\% \mathrm{SiO}_{2}\right)+8.65(\% \mathrm{CaO})+ \\
& -8.43\left(\% \mathrm{Al}_{2} \mathrm{O}_{3}\right)-13.86(\% \mathrm{MgO})+ \\
& -3.3\left(\% \mathrm{Na}_{2} \mathrm{O}\right)-2.2\left(\% \mathrm{~K}_{2} \mathrm{O}\right)-6.47(\% \mathrm{~F})+ \\
& -18.4(\% \mathrm{FeO})-3.2(\% \mathrm{MnO})-6.6\left(\% \mathrm{Li}_{2} \mathrm{O}\right)
\end{aligned}
$$

The dependence of $T_{b r}$ on mould flux viscosity, casting speed and the strand format is presented graphically in Fig. 1.

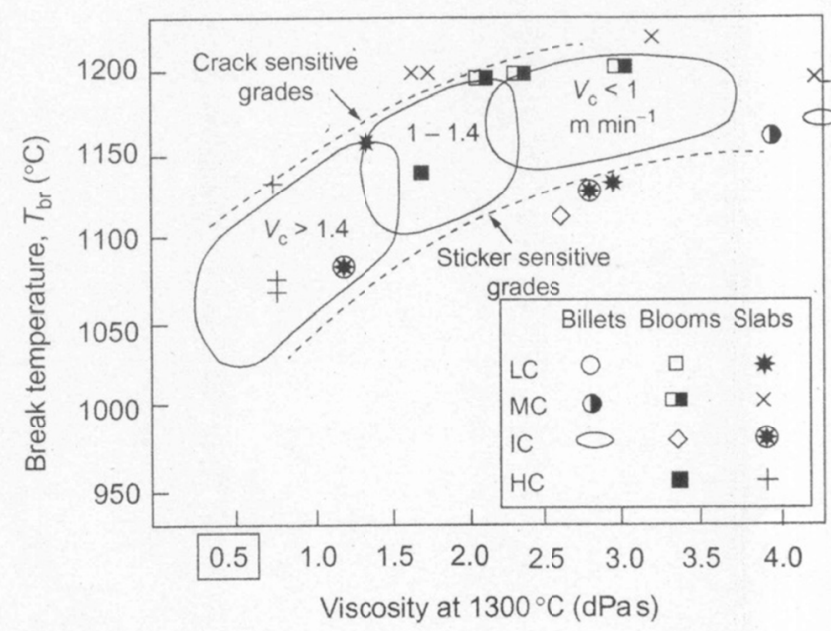

Fig. 1. $T_{b r}$ as a function of mould flux viscosity, casting speed and the strand format[1]

The lubricating properties of the mould flux depend both on its viscosity and the slag-metal interfacial tension. The interfacial tension is a function of the surface tensions of metal and slag.

$$
\sigma_{m s}=\sigma_{m}+\sigma_{s}-2 \Phi\left(\sigma_{m} \sigma_{s}\right)^{0.5}
$$

The $\varphi$ parameter for slags not containing $\mathrm{FeO}$ is 0.5 , and it grows when FeO appears. Tanaka et al. has proposed the following formula to determine $\varphi[6]$

$$
\Phi=0.5+0.3 X_{\mathrm{FeO}}
$$

The density of most mould fluxes stays at a relatively constant level and in the liquid state it is about $2500-2600 \mathrm{~kg} / \mathrm{m}^{3}$. Similarly, the specific heat $c_{p}$ is fairly constant and oscillates around $1.4 \mathrm{~J} / \mathrm{K} \mathrm{kg}$. For the solid state, at temperatures of 25 and $600^{\circ} \mathrm{C}$, it is 0.8 and $1.1 \mathrm{~J} / \mathrm{K} \mathrm{kg}$ respectively.

\section{Heat transport within the mould}

The intensity of heat extraction in the mould is key to the correct course of the casting process. For understandable reasons, the horizontal heat flux perpendicular to the mould walls and the vertical heat flux perpendicular to the meniscus should be considered separately. The thickness of the forming shell depends on the value of the horizontal heat flux and its determination is one of the key parameters of the continuous casting process [7]. The shell thickness can be accurately calculated with e.g. FEM methods. In a very simplified way it can be determined according to the formula:

$$
d_{\text {shell }}=K\left(d / V_{c}\right)^{0.5}
$$

where $d_{\text {shell }}$ is the shell thickness, $d$ is the distance from the meniscus to the end of the mould, and $K$ is the solidification constant. 
The temperature gradient on the cross-section of the cast strand is complex as the heat flow resistance in individual layers varies. A schematic of the temperature gradient in the mould is presented in Fig. 2.

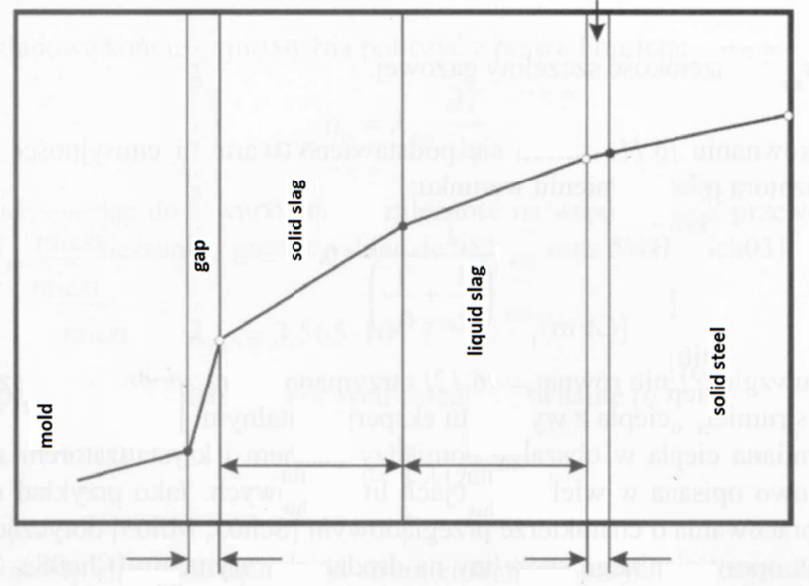

Fig. 2. The temperature gradient in the mould

In addition, mould oscillations influence the thickness of the forming shell. The oscillations generate a cyclical nature in the slag entrapment process and consequently the time-variable value of the horizontal heat flux extracted. On the basis of the conducted calculations one may find that:

- when the mould is ascended the heat flux is low, and the shell thickness increase is slowed down,

- when the mould is descended the heat flux increases, and the shell thickness increases,

- the heat flux and the shell growth rate are the highest at the bottom position of the mould.

Sometimes the presented effect may lead to the formation of the so-called "sausage shaped shell", Fig. 3.

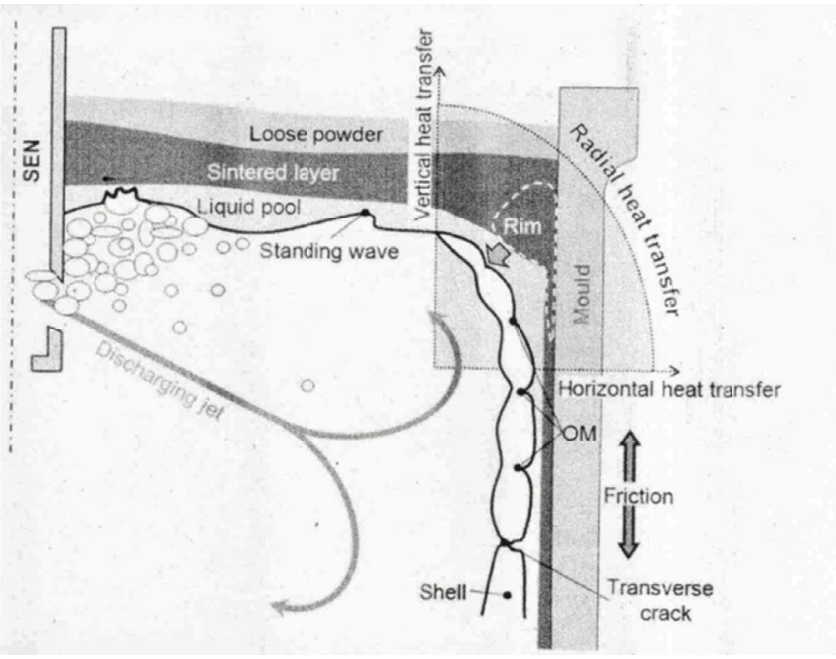

Fig. 3. Sausage shaped shell [1]

If the intensity of the heat extraction is very high, then the mentioned effect is enhanced and it may cause longitudinal cracks. Generally the horizontal heat flux is determined by the layer of solid slag and the share of crystalline phase in this layer.

The heat flux perpendicular to the meniscus largely depends on the mould flux properties. Also the proportions of the thicknesses of the mould flux layer as shown in Fig. 3 are relevant.

\section{The selection of the mould flux in the casting process}

The determination of the correct consumption of the mould flux requires first considering the $R^{*}$ parameter, which is the ratio of the circumference of the mould cross-section to the area of this cross-section. The $R^{*}$ formula is presented by the equation:

$$
R^{*}=2(w+t) / w t
$$

The consumption of the mould flux $Q_{\text {req }}^{\text {slag }}$ is a function of $R^{*}$ in the following form [1]:

$$
Q_{\text {req }}^{\text {slag }}=2 /\left(R^{*}-5\right)
$$

Apart from determining the mould flux consumption, it is also important to determine its required viscosity $\eta^{\text {req }}$ depending on its consumption and the planned casting speed $V_{c}$ :

$$
\eta^{r e q}=0.55 /\left(V_{c}^{2} Q_{r e q}^{\text {slag }}\right)
$$

Finally, the break temperature $T_{b r}$ is to be determined, which requires determining the $C P$ parameter (carbon potential) beforehand.

$$
\begin{aligned}
C P= & {[\% \mathrm{C}]+0.04[\% \mathrm{Mn}]+0.1[\% \mathrm{Ni}]+} \\
& +0.7[\% \mathrm{~N}]-0.14[\% \mathrm{Si}]-0.04[\% \mathrm{Cr}]+ \\
& -0.1[\% \mathrm{Mo}]-0.24[\% \mathrm{Ti}]
\end{aligned}
$$

Depending on the $C P$ parameter value, the break temperature is determined according to the following relationships:

$$
\begin{array}{ll}
\mathrm{CP}<0.06 \text { and } 0.18<\mathrm{CP}<0.4 & T_{b r}\left({ }^{\circ} \mathrm{C}\right)=1103+68,5 \ln \eta \\
0.06<\mathrm{CP}<0.18 & T_{b r}=1157+60 \ln \eta \\
\mathrm{CP}>0.4 & T_{b r}=1051+76,4 \ln \eta
\end{array}
$$

The consumption of the mould flux and its required viscosity can be determined on the basis of the casting process parameters. The proposed method of determination of these values shows a good conformity for about $85 \%$ of the mould fluxes applied.

\section{Experiment methodology}

The objective of the conducted research was to find out whether the method of mould powder feeding into the mould can cause fluctuations in mould flux properties. It was assumed that the main cause of variations is the assimilation of inclusions in the form of $\mathrm{Al}_{2} \mathrm{O}_{3}$. The tests were conducted for two types of mould fluxes. Their chemical constitution and most important physical properties are presented in Tables 1 and 2 . 
TABLE 1 that the heating rate was low within the temperature range in

Chemical constitution of mould fluxes

\begin{tabular}{|l|c|c|c|c|c|c|c|}
\hline & $\mathrm{SiO}_{2}$ & $\mathbf{C a O}$ & $\mathbf{M g O}$ & $\mathbf{A l}_{2} \mathbf{O}_{3}$ & $\mathbf{N a}_{2} \mathbf{O}$ & $\mathbf{K}_{\mathbf{2}} \mathbf{O}$ & $\mathbf{F e}_{2} \mathbf{O}_{3}$ \\
\hline Mould flux 1 & 31.2 & 37.1 & 1.1 & 5.8 & 6.5 & 0.7 & 1.0 \\
\hline Mould flux 2 & 30.3 & 39.4 & 2.3 & 3.3 & 7.8 & $\max 0.7$ & $\max 1.0$ \\
\hline
\end{tabular}

\begin{tabular}{|l|c|c|c|c|c|c|}
\hline & $\mathbf{M n O}_{2}$ & $\mathbf{F}$ & $\mathbf{C}_{\text {free }}$ & $\mathbf{C O}_{\mathbf{2}}$ & $\mathbf{C}_{\text {total }}$ & $\mathbf{H}_{\mathbf{2}} \mathbf{O}_{\left(\mathbf{1 0 5} 5^{\circ} \mathbf{C}\right)}$ \\
\hline Mould flux 1 & 0 & 10 & 4.1 & 4.6 & 5.3 & 0.4 \\
\hline Mould flux 2 & $\max 0.5$ & 7.7 & 3.0 & 5.6 & - & 0.5 \\
\hline
\end{tabular}

TABLE 2

Physical properties of mould fluxes

\begin{tabular}{|c|c|c|c|c|c|}
\hline \hline & $\begin{array}{c}\text { Softening } \\
\text { point }\left[{ }^{\circ} \mathbf{C}\right]\end{array}$ & $\begin{array}{c}\text { Melting } \\
\text { point } \\
{\left[{ }^{\circ} \mathbf{C}\right]}\end{array}$ & $\begin{array}{c}\text { Bulk } \\
\text { density } \\
{\left[\mathbf{k g} / \mathbf{d m}^{3}\right]}\end{array}$ & $\begin{array}{c}\text { Basicity } \\
{[-\mathbf{~}}\end{array}$ & $\begin{array}{c}\text { Surface tension } \\
\text { at } \mathbf{1 3 0 0}{ }^{\circ} \mathbf{C}, \\
{[\mathbf{m N} / \mathbf{m}]}\end{array}$ \\
\hline $\begin{array}{c}\text { Mould } \\
\text { flux 1 }\end{array}$ & 1085 & 1150 & 0.7 & 1.19 & 344 \\
\hline $\begin{array}{c}\text { Mould } \\
\text { flux 2 }\end{array}$ & 1090 & 1140 & 0.75 & 1.3 & - \\
\hline
\end{tabular}

In the experiment, slag was sampled at equal time intervals of $1 \mathrm{~min}$, between feeding the subsequent portions of the mould powder. The samples were taken from the liquid layer of the mould flux adjoining the steel meniscus by being frozen on a metal rod. The obtained material of the mould slag was then ground in a mill. Changes in the mould flux properties were assessed by measuring the liquidus temperature within a high-temperature microscope of Leitz ${ }^{\circledR}$. In order to stabilise the measurement conditions in all cases the same sample heating schedule was applied, as presented in Table 3.

TABLE 3

Sample heating schedule

\begin{tabular}{|c|c|}
\hline \hline Temperature range $\left[{ }^{\circ} \mathbf{C}\right]$ & Heating rate $\left[{ }^{\circ} \mathbf{C} / \mathbf{m i n}\right]$ \\
\hline $0-700$ & 60 \\
\hline $700-920$ & 20 \\
\hline $920-1500$ & 5 \\
\hline
\end{tabular}

The heating schedule allowed a much higher temperature than the measurement temperature, but the experiment would always be finished after melting the sample. It was important which the most important transformations occurred.

\section{Measurement results}

For each of the analysed mould fluxes, 5 slag samples were taken as the time between mould powder applications was extended to $4 \mathrm{~min}$. The collected test material allowed us to determine the melting temperature with an accuracy up to $5^{\circ} \mathrm{C}$. The selected pictures of mould slag samples are presented in Fig. 4. The temperature readings are presented in Table 4.

TABLE 4

Melting temperatures of slag samples taken from the mould between the subsequent operations of mould powder feeding

\begin{tabular}{|c|c|c|c|c|c|}
\hline \hline $\begin{array}{c}\text { Sampling time } \\
\text { [min] }\end{array}$ & $\mathbf{0}$ & $\mathbf{1}$ & $\mathbf{2}$ & $\mathbf{3}$ & $\mathbf{4}$ \\
\hline & \multicolumn{5}{|c|}{ Melting point [ $\left.{ }^{\circ} \mathbf{C}\right]$} \\
\hline Mould flux 1 & 1125 & 1165 & 1095 & 1135 & 1270 \\
\hline Mould flux 2 & 1145 & 1125 & 1136 & 1150 & 1165 \\
\hline
\end{tabular}

Changes in the liquidus temperature are illustrated graphically in Fig. 5. It should be emphasised that the stability of the melting temperature for mould flux 2 is better than for mould flux 1 . Moreover, for mould flux 2, a monotonous effect of the liquidus temperature change caused by the surfacing $\mathrm{Al}_{2} \mathrm{O}_{3}$ inclusions can be observed from the first minute, but the range of this change is relatively small. Taking into account the actual time between feeding the subsequent portions of the mould flux, one can find that mould flux 2 meets its requirements. The data scatter for mould flux 1 may have various grounds but the instability of the chemical constitution seems most likely.

\section{Conclusion}

The correct course of the steel continuous casting process depends on many factors, amongst which the correct selection of the mould powder and its quality play a very significant role. Apart from the initial parameters, such as the mould flux chemical constitution and the intensity of its feeding, the assumed casting parameters, i.e. the steel temperature and the casting speed

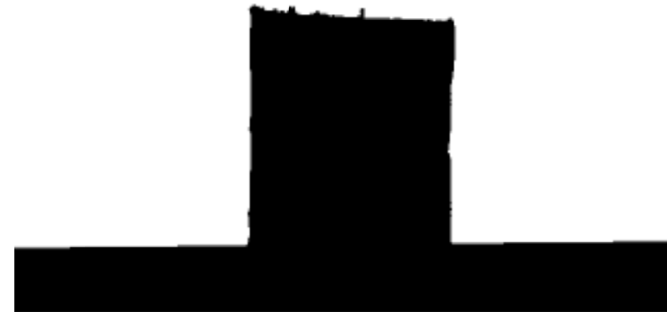

a)

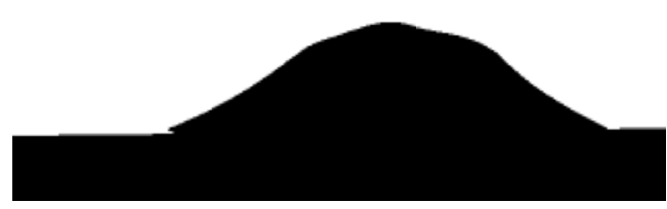

b)

Fig. 4. The result of measurements with a high-temperature microscope for mould flux 2, taken in the second minute after being fed into the mould, a) temp. $920^{\circ} \mathrm{C}$, b) temperature $1136^{\circ} \mathrm{C}$ 


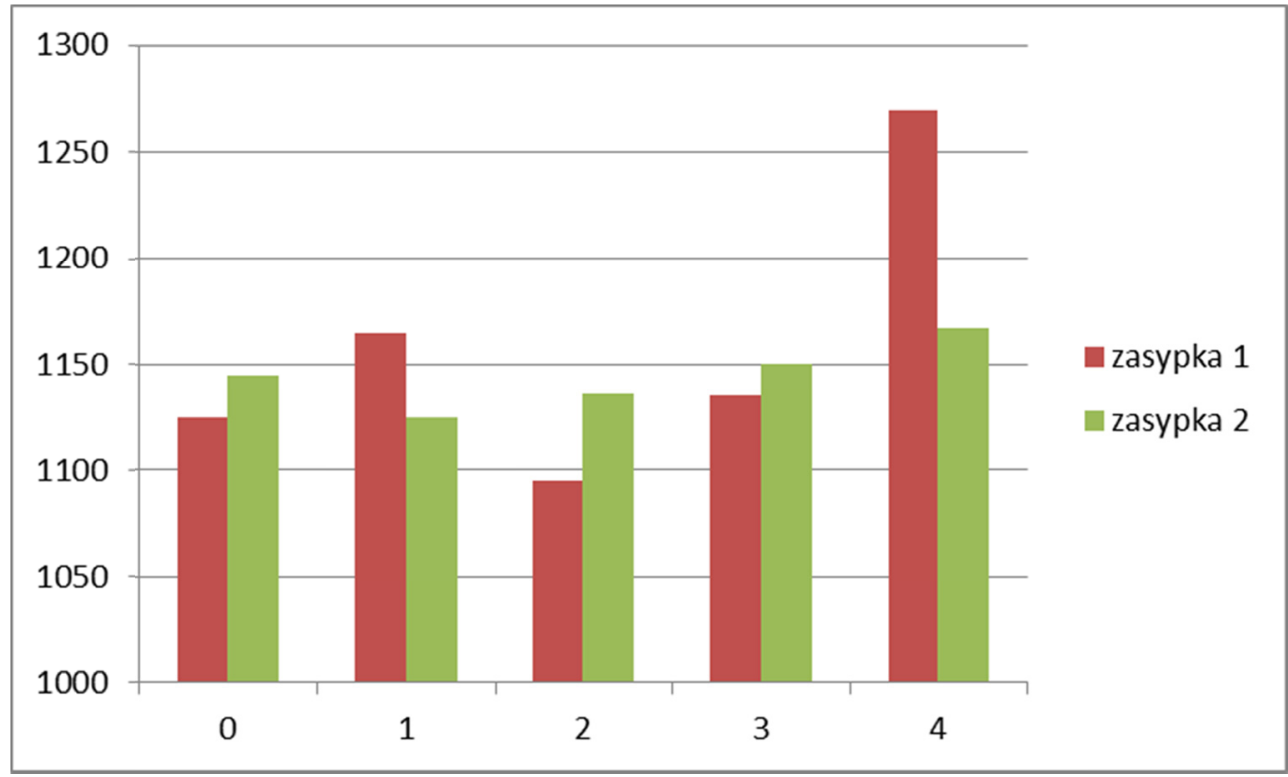

Fig. 5. The change in the value of the liquidus temperature of the mould slag as a function of casting time

are very important. A change in the mould flux constitution during casting depends largely on the chemical composition of the steel cast. Automation of the mould powder feeding process significantly reduces the risk of a change in its constitution. The conducted research showed that deviations from the adopted casting procedure make the possibility of occurrence of flaws resulting from the changing chemistry of the mould flux in the mould more likely.

\section{Acknowledgments}

This research work was financed through statutory funds at AGH University of Science and Technology 11.11.110.293

\section{REFERENCES}

[1] S. Seetharaman (Ed.), Industrial Processes, Part A, 2014 Elsevier, Waltham.

[2] T. Schulz, B. Lychatz, N. Haustein, D. Janke, Metall. and Materi. Trans. B 44B (4), 317-327 (2013).

[3] T. Schulz, D. Janke, H.-P. Heller, B. Lychatz, Stahl und Eisen, 128 (4), 65-73 (2008).

[4] J. Lamut, J. Falkus, B. Jurjevec, et al., Arch. Metall. Mater. 57, 1, 319-324 (2012)

[5] A. Cwudziński, J. Jowsa, in: T. Chandra, N. Wanderka, W. Reimers et al. (Ed.), $6^{\text {th }}$ International Conference on Processing and Manufacturing of Advanced Materials, Berlin Aug. 25-29, 209, Thermec 2009, PTS 1-4 Book Series: Materials Science Forum V. 638-642, 3176-3181, Part 1-4, published 2010.

[6] T. Tanaka, M. Nakamoto, J. Lee, at al. in: R.E. Aune, M. Kekkonen (Ed.), Proceedings of Metal Separation Technology held Copper Mountain, Helsinki University of Technology, June 2004, 135-142

[7] M. Tadleckova, K. Michalek, P. Machovcak: 24th International Conference on Metallurgy and Materials, Tanger Ltd, Brno Czech Republic, 2015, 54-59. 